\title{
Global analysis of fish growth rates shows weaker responses to temperature than metabolic predictions
}

van Denderen, Daniël; Gislason, Henrik; van der Heuvel, Joost; Andersen, Ken H.

Published in:

Global Ecology and Biogeography

Link to article, DOI:

10.1111/geb.13189

Publication date:

2020

Document Version

Peer reviewed version

Link back to DTU Orbit

Citation (APA):

van Denderen, D., Gislason, H., van der Heuvel, J., \& Andersen, K. H. (2020). Global analysis of fish growth rates shows weaker responses to temperature than metabolic predictions. Global Ecology and Biogeography, 29(12), 2203-2213. https://doi.org/10.1111/geb.13189

\section{General rights}

Copyright and moral rights for the publications made accessible in the public portal are retained by the authors and/or other copyright owners and it is a condition of accessing publications that users recognise and abide by the legal requirements associated with these rights.

- Users may download and print one copy of any publication from the public portal for the purpose of private study or research.

- You may not further distribute the material or use it for any profit-making activity or commercial gain

- You may freely distribute the URL identifying the publication in the public portal 
1 Global analysis of fish growth rates shows weaker responses to

2 temperature than metabolic predictions

3 Running title: Fish growth and temperature

4

5 P. Daniël van Denderen ${ }^{1}$, Henrik Gislason ${ }^{1}$, Joost van de Heuvel ${ }^{2}$ and Ken H. Andersen ${ }^{1}$

$6{ }^{1}$ Centre for Ocean Life, National Institute of Aquatic Resources, Technical University of

7 Denmark, Kemitorvet B-202, 2800 Kongens Lyngby, Denmark

$8 \quad{ }^{2}$ Laboratory of Genetics, Wageningen University, Wageningen, the Netherlands

10 Corresponding author: P. Daniël van Denderen; E-mail: pdvd@aqua.dtu.dk; Address: Technical

11 University of Denmark, Kemitorvet B-202, 2800 Kongens Lyngby, Denmark 


\section{Abstract}

13 Aim: Higher temperatures increase the metabolic rate of ectotherm organisms up to a certain level

14 and make them grow faster. This temperature-sensitivity of growth is frequently used to predict

15 the long-term effects of climate warming on ectotherms. Yet, realized growth also depends on

16 ecological factors and evolutionary adaptation. Here we study whether faster growth is observed

17 along temperature clines within- and between marine fish species from polar to tropical regions.

18 Location: Global

19 Time period: The sampling or publication year is for 718 observations before 1980, 1073

20 observations between 1980-2000 and 390 observations after 2000 (for 336 observations no year

21 was recorded).

22 Major taxa studied: Marine teleost fish and elasmobranchs

23 Methods: The effects of temperature on fish growth are studied using 2517 growth observations,

24 representing 771 species in 165 marine ecoregions. The effects of temperature are presented with

25 a $Q_{10}$, describing relative increase in the rate of growth for each $10^{\circ} \mathrm{C}$ increase.

26 Results: We find weak within- and between-species effects of temperature on growth. The typical

27 within-species effect of temperature has a $Q_{10}$ of 1.1 . The between-species effect is a little higher

$28\left(Q_{10}=1.4\right.$, or $Q_{10}=1.2$ when corrected for phylogenetic relationships). When analyzed per fish

29 guild, growth responses vary from nearly independent of temperature in large demersals $\left(Q_{10}=\right.$

30 1.1) to positive in small pelagics $\left(Q_{10}=1.6\right)$ and elasmobranchs $\left(Q_{10}=2.3\right)$. Average growth is

31 higher in ecoregions with high primary production. 
32 Main conclusion: The change in average growth along temperature clines is weaker than predicted

33 by metabolic theory, suggesting that the metabolic predictions are not sustainable in an ecosystem

34 context. The long-term response of fish to the increase in temperature associated with climate

35 change may hence be shaped more by local environmental and ecological dynamics than by the 36 physiological temperature response of the present species.

37

38 Keywords: Climate change, ectotherms, metabolic theory, marine fish, temperature response, von

39 Bertalanffy growth 


\section{Introduction}

41 Making credible predictions of the response of individuals, populations and communities to

42 changing temperatures with climate change is a pressing challenge in current ecology. Most

43 organisms are ectotherms and temperature directly influences their physiology, thereby changing

44 somatic growth. Somatic growth (hereafter growth) is typically observed to increase with

45 temperature to a certain optimum after which it decelerates (Kingsolver, 2009). The increase in

46 growth is predicted to scale with temperature in the same way as the metabolic rate, hence with a

$47 \approx 2.5$-fold increase for each $10^{\circ} \mathrm{C}$ increase in temperature (Brown, Gillooly, Allen, Savage \& West,

48 2004; Grady, Enquist, Dettweiler-Robinson, Wright \& Smith, 2014). This metabolic temperature-

49 sensitivity of growth is included in most modelling studies that predict the long-term effects of

50 changing temperatures due to climate change on ectotherm organisms, from individuals to

51 communities and from local environments to the global ocean, e.g. for fish see Cheung,

52 Bruggeman \& Butenschön (2018) and Carozza, Bianchi \& Galbraith (2019), see for an alternative

53 approach O'Gorman et al. (2019).

54 The effects of temperature on growth have been studied extensively in the laboratory where food

55 and predators can be manipulated (Atkinson, 1994; Jobling, 1997; Kremer, Thomas \& Litchman,

56 2017). The effects are more difficult to study in natural environments where resource availability,

57 predation risk and the length of the growing season are not easily manipulated (Arendt, 1997;

58 Clarke, 2003). So far, the length of the growing season has gained most attention as it is inversely

59 correlated to temperature at large spatial scales and has been found to reverse the effect of

60 temperature on growth among populations within species, in some cases even resulting in counter-

61 gradient variation in growth within species, i.e. faster growth among populations that live in colder

62 waters (Conover \& Present, 1990). Between species, the effect of temperature on growth is further 
63 confounded by differences in phylogeny and ecology, e.g. by prey types, habitats, and lifestyles,

64 that may vary systematically with temperature. Despite the confounding factors that affect the

65 within- and between-species effect of temperature on growth, models describing ectotherm growth

66 in natural environments are typically inspired by the framework proposed by metabolic theory and

67 parameterize the temperature sensitivity of growth assuming it follows metabolic predictions

68 (Blanchard et al., 2012; Cheung et al., 2013). Empirical support for these growth patterns with 69 temperature is limited in natural systems.

70 Here we investigate how temperature influences the realized growth rates of marine fish in nature

71 from polar to tropical environments considering both within and between fish species changes in

72 growth. The effect of temperature on growth is in this study presented with a $Q_{10}$, describing the

73 relative increase in the rate of growth for each $10^{\circ} \mathrm{C}$ increase in temperature. Metabolic theory

74 predicts that growth is fueled by metabolism and that both scale with temperature following the

75 Arrhenius equation and with a $Q_{10}$ of approximately 2.5 (Brown et al., 2004). Previous work on

76 the between-species effect of temperature on marine fish growth in natural environments suggests

77 that the rate of increase with temperature is likely to be lower than the metabolic predictions, with

$78 Q_{10 \text { s }}$ ranging between 1.5 and 2 (Clarke, 2017; Edgar \& Shaw, 1995; Sibly et al., 2015). We extend

79 this body of work using a larger dataset to explore if there are systematic differences between the

80 within- and between-species effects of temperature on growth. We hypothesize that the typical

81 within-species effect is stronger, and hence closer to the metabolic predictions, than the between-

82 species effect, which is likely to be lower due to the evolutionary adaptation of species to their

83 habitats and selection of life histories through community assembly (Fig. 1). We furthermore test

84 whether the between-species relationship between temperature and growth depends on phylogeny

85 and fish guild, where guild is defined as a group of species that exploit the same resource and have 
86 a similar ecological niche. Lastly, we examine if growth varies consistently with regional changes

87 in feeding conditions, as growth ultimately depends on the rate of energy acquisition throughout 88 ontogeny.

89 We find weaker within- and between-species effects of temperature on growth than derived from 90 metabolic predictions. These results do not invalidate temperature effects as predicted by 91 metabolic theory at the individual level, but show that such predicted growth trajectories with 92 temperature are not sustainable in an ecosystem context, potentially resulting from evolutionary 93 adaptation of species to their habitats and selection of life histories through community assembly. 94 Consequently, modelling studies based on metabolic theory are likely to predict much stronger 95 long-term effects of temperature change with climate change than might occur. Our results provide 96 improved empirical constrains of temperature on fish growth and highlight that understanding 97 natural variation in growth with temperature not only requires a correct description of the 98 physiological response to temperature, but also of the ecological dynamics. 


\section{Methods}

100 In the marine fish literature, growth is generally described with the von Bertalanffy growth model.

101 This model contains the von Bertalanffy parameters $L_{\infty}$ and $K$, where $L_{\infty}$ is the asymptotic length 102 and $K$ the von Bertalanffy growth constant. We used von Bertalanffy parameters from FishBase 103 (Froese \& Pauly, 2018) to derive an estimate of growth, termed growth coefficient $A$, and examined 104 the effects of temperature, fish guild, phylogeny and food availability on $A$.

\section{Growth coefficient $A$}

106 The von Bertalanffy growth model describes the rate of growth in body weight, $\mathrm{d} w / \mathrm{d} t$, as the 107 difference between acquisition of energy, $A w^{2 / 3}$, and losses, $f w$ (Von Bertalanffy, 1957):

$108 \quad \frac{\mathrm{d} w}{\mathrm{~d} t}=A w^{2 / 3}-f w^{1}$ eq. 1

109 where coefficients $A$ and $f$ describe the overall magnitude of the processes, while the exponents $n$ 110 and 1 describe how they scale with body weight, w. Von Bertalanffy argued that acquisition of 111 energy is limited by processes that involve absorbing oxygen or food across a surface (gills or the 112 digestive system) and therefore scales with size raised to a power $2 / 3$, whereas losses can be 113 assumed to scale linearly with weight. Modern interpretations of eq. 1 use an exponent 3/4 (West, 114 Brown \& Enquist, 2001), but we use 2/3 because it conforms with available data (see later), and 115 because the exact value of the exponent is of limited importance in this context.

116 The above formulation (eq. 1) implies that the specific growth rate of fish, $(\mathrm{d} w / \mathrm{d} t) / w$ is initially 117 high and mainly dependent on growth coefficient $A$ (appendix $\mathrm{S} 1$ in supporting information, Fig. $118 \mathrm{~S} 1.1$ ). The higher the value of $A$, the faster individuals grow, and we therefore refer to $A$ as the 119 growth coefficient, see further Charnov, Gislason \& Pope (2013) and Andersen (2019).

120 Empirical estimates of growth are done with the length-based version of the von Bertalanffy 
121 equation:

$122 \quad \frac{\mathrm{d} l}{\mathrm{~d} t}=K\left(L_{\infty}-l\right)$

eq. 2

123 where $L_{\infty}$ is the asymptotic length in $\mathrm{cm}$ and $K$ is the von Bertalanffy growth constant with units

124 year ${ }^{-1}$. Using the standard relation between length and weight $w=c l^{3}$ (Froese, 2006), eq. 1 and eq.

1252 are identical if $K=f / 3=1 / 3 A c^{-1 / 3} / L_{\infty}$, which provides a way to calculate $A$ from reports of

$126 K$ and $L_{\infty}$. With the condition factor $c\left(\mathrm{~g} \mathrm{~cm}^{-3}\right)$ assumed to be constant across fish species $(c=0.01)$

127 (Froese, 2006), the growth coefficient is $A=c^{1 / 3} 3 K L_{\infty}=0.65 K L_{\infty}$. We verified in appendix S2

128 Table S2.1 that a species-specific length-weight relationship gives consistent results.

129 To obtain growth coefficient $A$ estimates, we extracted von Bertalanffy $L_{\infty}$ and $K$ parameters from 130 FishBase (Froese \& Pauly, 2018) on 27 April 2018 for all marine fish species using the R-package

131 'rfishbase' (Boettiger, Lang \& Wainwright, 2012). We selected fish species where the von 132 Bertalanffy parameters $\left(L_{\infty}\right.$ and $\left.K\right)$ were reported and where $t_{0}$, describing the point in time or age 133 (in years) where the growth curve intersects the abscissa (the theoretical age at which the model 134 predicts the fish species to have zero length), was in the range $[-2,2]$ for teleost and $[-5,2]$ for 135 elasmobranchs because the latter often are born at a larger size. A $t_{0}$ outside this range indicates 136 insufficient or biased data, a poor model fit and/or a systematic error in the procedure to estimate 137 fish age. By selecting growth data from fish with a reported $t_{0}$, we made sure that our growth 138 analysis only included estimates of fish based on length-at-age data and age readings, avoiding 139 estimates based on subjective interpretation of peaks in length-frequency data from which absolute 140 age and hence $t_{0}$ cannot be estimated. The length-at-age is typically collected from catch or trawl 141 survey data. 
142 We manually linked each growth observation from FishBase to a particular marine ecoregion or

143 to two neighboring ecoregions (Spalding et al., 2007) when the sampling locality was provided.

144 All data with indistinct, missing or unwanted (e.g. laboratory, rivers) localities or duplicated

145 observations were removed. We also removed all species from the genera Huso, Acipenser,

146 Anguilla, Salmo and Oncorhynchus that were classified as marine but mainly grow in freshwater

147 and all oceanic elasmobranchs (16 species, following the classification of Compagno (2008)) that

148 live in a different habitat than their shallow-water counterparts. This resulted in 2517 observations

149 of growth coefficient $A$ representing 771 species in 165 ecoregions (Fig. 2). The sampling year

150 and/or publication year was before 1980 for 718 observations, between 1980 and 2000 for 1073

151 observations, and after 2000 for 390 observations (for 336 observations no year was recorded in

152 the database).

$153 \quad$ Fish guild classification

154 We classified fish species into one of four guilds: pelagic, demersal, deep-living and 155 elasmobranchs, following the functional group classification from the SeaAroundUs project 156 (seaaroundus.org) (appendix S1, Table S1.1). When fish were not classified in the SeaAroundUs 157 project, we used the feeding type/habitat description from FishBase and checked for 158 elasmobranchs.

\section{Environmental temperature and food conditions}

160 For each ecoregion, we derived estimates of temperature, zooplankton fish prey biomass and 161 production, and net primary production. Temperature and zooplankton estimates representative of 162 the early 1990s were derived from a global earth system model (GFDL-ESM2.6) coupled to a 163 Carbon, Ocean Biogeochemistry and Lower Trophic levels (COBALT) planktonic ecosystem 164 model (Stock, Dunne \& John, 2014; Stock et al., 2017); net primary production was derived from 
165 the Vertically Generalized Production Model using MODIS data between 2003 and 2014

166 (Behrenfeld \& Falkowski, 1997). Because fish differ in their position in the water column, we

167 calculated the most likely ambient temperature (hereafter termed temperature) for each fish guild

168 in the water column. Temperature for pelagic fish was defined as the average temperature in the

169 upper 100 meter, temperature for demersal fish and elasmobranchs as the average near the bottom

170 at depths < 500 meter, and temperature for deep-living fish as the average near the bottom at

171 depths $>=500$ meter. Further details on the environmental conditions are provided in appendix S3.

172 Note that we did not include the length of the growing season as an environmental parameter as it

173 is strongly correlated with temperature (but see discussion).

$174 \quad$ Data analysis

175 The effects of temperature on growth coefficient $A$ were examined using within- and between-

176 subject centering (van de Pol \& Wright, 2009) in a stepwise process where we gradually increased

177 the complexity of the statistical model. All models were mixed effect models with species and

178 ecoregion as two separate random factors; for information on mixed effect models see e.g. Zuur et

179 al. (2009). In each analysis, growth coefficient $A$ was $\log _{10}$ transformed. Our main analysis ignores

180 non-linearities in the shape of the growth curve with temperature, as we did not find indications

181 that such non-linearities are generic (see further discussion and appendix S4).

182 Within- and between-species effects of temperature on growth

183 First, we examined a mixed model where we separated the effect of temperature on growth for the 184 within- and between-species components:

$185 \log _{10}\left(A_{i j r}\right)=\left(\beta_{0}+v_{0 j}+v_{0 r}\right)+\beta_{W}\left(T_{i j r}-\bar{T}_{j}\right)+\beta_{B} \bar{T}_{j}+e_{0 i j r}$ 
186 In this formulation, $i$ refers to an individual observation of species $j$ in ecoregion $r$. The intercept 187 was determined by the fixed effect $\beta_{0}$ and the random effect of species $v_{0 j}$ and ecoregion $v_{0}$. The random intercepts and the residual error $e_{0 i j r}$ were assumed to be normally distributed. The within189 species effect $\beta_{W}$ was determined by subtracting the mean temperature $\bar{T}_{j}$ of species $j$ from the 190 temperature $T_{i j r}$ of each individual observation of species $j$ in ecoregion $r$. The between-species 191 effect $\beta_{B}$ was determined from the mean temperature $\bar{T}_{j}$ of each species.

192 Next, we determined whether there was a significant difference in the slopes of the within- and 193 between-species effect of temperature on growth coefficient $A$. The difference between the within194 and between-species effect is the difference between $\beta_{W}$ and $\beta_{B}$. The statistical significance of this 195 difference was obtained by contrasting the estimated slope parameters (van de Pol \& Wright, 196 2009).

197 In the second model, we investigated whether there was between-species variation in the slopes of 198 the within-species effect of temperature on growth by adding a random slope $v_{W j}$ to the random 199 species intercept:

201 Models M1-M2 were fitted using the R-package 'lme4' (Bates, Mächler, Bolker \& Walker, 2015) 202 and p-values were estimated using Satterthwaite's method from the 'LmerTest' R-package 203 (Kuznetsova, Brockhoff \& Christensen, 2017). In all calculations, we calculated $Q_{10}$ as $204 A_{T 2} / A_{T 1}{ }^{10 /\left(T_{2}-T_{1}\right)}$ with $\mathrm{T}$ in ${ }^{\circ} \mathrm{C}$, where the values of $A$ are the predicted growth coefficients from 205 the statistical model. The terms $\beta_{B}$ and $\beta_{W}$ in M1 were used to estimate a within- and between206 species $Q_{10}$ and $95 \%$ confidence intervals were calculated for $\beta_{B}$ and $\beta_{W}$ (and the $Q_{10}$ associated 207 with the 95\% CI of these coefficients) using the 'confint' function, which computes a likelihood 
profile. In M2, a $Q_{10}$ was estimated for each individual species based on the fixed and random effect $\beta_{W}+v_{W j}$. All estimated coefficients are shown in appendix S1, Table S1.2. Visual inspections of model fit are shown in appendix S5. We did not include fish asymptotic length in M1-M2. Yet, note that fish asymptotic length does not systematically vary over the temperature gradient (appendix S1, Fig. S1.2).

\section{Role of phylogeny on the between-species effect of temperature on growth}

Phylogenetic relatedness may affect the between-species effect of temperature on growth coefficient $A$ when a phylogenetic group is dominant at low and/or high temperatures and driving the slope of the overall relationship. We used the Fish Tree of Life from the R-package 'fishtree' (Chang, Rabosky, Smith \& Alfa, 2019; Rabosky et al., 2018) to construct a phylogenetic covariance matrix that describes the phylogenetic relatedness between species. In this analysis, we assumed that species are likely to share similar growth rate values when their phylogenetic relatedness is high. The expected variance of the growth rate values is assumed to follow the Brownian motion model of trait evolution and is, as such, proportional to the phylogenetic distance (Felsenstein, 1985).The phylogenetic analysis was only done for a subset of 613 fish species for which data was available and this excluded all elasmobranchs. The effect of phylogeny was tested for the data subset with (and without) a phylogenetic covariance matrix (M) and a similar model structure as M2 using the R-package 'MCMCglmm' (Hadfield, 2010):

$\log _{10}\left(A_{i j r}\right)=\left(\beta_{0}+v_{0 j}+v_{0 r}\right)+\left(\beta_{W}+v_{W j}\right)\left(T_{i j r}-\bar{T}_{j}\right)+\beta_{B} \bar{T}_{j}+e_{0 i j r}+M$.

\section{Role of fish guilds on the between-species effect of temperature}

We determined the importance of fish guild and asymptotic length to explain variation in the between-species effect of temperature on growth coefficient $A$. We tested different mixed models 
230 that varied from a three-way interaction (mean temperature $\bar{T}_{j}$ of each species $\cdot$ the $\log _{10}$ of mean 231 asymptotic length $\bar{L}_{j}$ of each species - fish guild $G_{j}$ ) to no interaction. Models were fitted in a 232 similar way as M1-M2. Model selection was based on evaluating Akaike's Information Criterion 233 (AIC). Model selection is described in appendix S1, Table S1.3. The model that best fit the data is 234 presented here:

$\log _{10}\left(A_{i j r}\right)=\left(\beta_{0}+v_{0 j}+v_{0 r}\right)+\left(\beta_{W}+v_{W j}\right)\left(T_{i j r}-\bar{T}_{j}\right)+\beta_{B 1} \bar{T}_{j}+\beta_{B 2} \bar{L}_{j}+\beta_{B 3} G_{j}+$ $\beta_{B 4} \bar{T}_{j} \bar{L}_{j}+\beta_{B 5} \bar{T}_{j} G_{j}+e_{0 i j r} . \quad \mathrm{M} 4$

237 To test the robustness of the predictions in M4, we also examined the effects of temperature, guild 238 and asymptotic length on growth coefficient $A$ in four additional analyses while selecting $i$ ) all 239 teleost data with a $t_{0}$ between -1 and 1 and elasmobranch data with a $t_{0}$ between -5 and 1 , ii) the 240 maximum growth coefficient $A$ for each species, iii) all data while including a phylogenetic 241 covariance matrix and $i v$ ) all data while using the mean temperature of the coldest and warmest 242 calendar quarter per ecoregion instead of a yearly average.

\section{Variation in growth across marine regions}

244 We did not incorporate regional variation in food conditions in our statistical analysis, since our 245 study is focused on the effect of temperature. Yet, we explored whether zooplankton production, 246 zooplankton biomass or net primary production can explain variation in the estimated random 247 ecoregion intercept $v_{0 r}$ taken from the results of M4. This was done for all regions where we have 248 data for more than 10 different fish species. 


\section{Results}

250 Within- and between-species effects of temperature on growth

251 Our results show that the average growth coefficient $A$ between fish species is positively related 252 to temperature when all fish data is pooled $\left(Q_{10}=1.38,95 \%\right.$ CI 1.29-1.49, M1, Fig. 3a). The within253 species effect of temperature is weaker $\left(Q_{10}=1.14,95 \%\right.$ CI $\left.1.05-1.26, \mathrm{M} 1\right)$ than the between254 species effect and the difference in the within- and between-species effect is significant ( $p$-value $255<0.001)$

256 By allowing between-species variation in the slopes of the within-species effect (M2), we find that 257 species differ in how strongly growth coefficient $A$ depends on temperature (M2 provides a better 258 fit to the data than M1, see appendix S1 Table S1.4). The results show that growth coefficient $A$ 259 declines for some species with increasing temperature $\left(Q_{10} \approx 0.5\right)$ and increases strongly for others $260\left(Q_{10}>2.0\right)$ (Fig. 3b and appendix S1, Fig. S1.3). The average within-species relationship between 261 temperature and growth coefficient $A$ is weak (average $Q_{10}=1.08, \mathrm{M} 2$ ).

262 Role of phylogeny on the between-species effect of temperature on growth

263 For a subset of 613 fish species for which phylogenetic data were available, we find a similar 264 between-species effect of temperature on growth coefficient $A$ as in M1 without phylogeny $\left(Q_{10}=\right.$ $2651.36,95 \%$ CI 1.27-1.46). Including phylogenetic signal lowers the between-species effect of 266 temperature on growth coefficient $A\left(Q_{10}=1.21,95 \%\right.$ CI 1.11-1.33, M3).

267 Role of fish guilds on the between-species effect of temperature

268 Our results show that the between-species effect of temperature varies as a result of fish feeding 269 guild and fish asymptotic length. We find most support for a model with a two-way interaction 270 between temperature and fish guild and between temperature and asymptotic length (see appendix 
271 S1, Table S1.2). The model predicts that average growth among demersal and deep-living fish (but

272 note the restricted temperature range for deep-living fish) is weakly affected by temperature,

273 whereas average growth among pelagic fish and elasmobranchs increase more strongly (Fig. 4).

274 Temperature effects on average growth decline with increasing asymptotic length. The model in

275 M4 also estimates between-species variation in the slopes of the within-species effect of 276 temperature on growth coefficient $A$. These estimates follow the findings in M2 (average within-

277 species $\mathrm{Q}_{10}=1.08$ in M2 and 1.12 in M4), despite some variation in individual species (not shown).

278 Using the M4 model outcome, we compare average growth for each fish guild across a temperature 279 gradient for two asymptotic lengths $\left(30\right.$ and $100 \mathrm{~cm}$ ) (Fig. 5). In waters $<5^{\circ} \mathrm{C}$, the average growth 280 of fish with $L_{\infty}=100 \mathrm{~cm}$ is equally fast for demersals and deep-living fish (large pelagics are not 281 included as there is no data available on large pelagics in this temperature range), whereas large 282 elasmobranchs and species with $L_{\infty}=30 \mathrm{~cm}$ grow slower. In waters $>20^{\circ} \mathrm{C}$, average growth is 283 highest in large elasmobranchs and pelagic fish, whereas demersal fish grow slower due to a 284 weaker temperature effect on growth.

285 The effect of temperature on the different guilds is robust when compared with other methods of 286 data selection, when corrected for phylogenetic signal or when the coldest or warmest calendar 287 quarter is used instead of a yearly average temperature (appendix S1, Table S1.5). The $Q_{10}$ 288 maximally varies \pm 0.2 with the results in the main analysis.

289 Growth variability across marine regions

290 For all regions with data on more than 10 fish species, we find a positive relationship between 291 growth coefficient $A$ and net primary production (NPP) $\left(\log _{10}(A)=-0.07+0.08(N P P)\right.$, p292 value $=0.005$, adjusted $\left.\mathrm{R}^{2}=0.20\right)($ Fig. 6a). The results show that the ecoregion random intercept 
293 varies \pm 0.1 over the NPP gradient. This variation in the random intercept corresponds to a 1.3 -

294 fold increase in growth coefficient $A$ over a 4-fold increase in NPP (the 1.3-fold increase is 295 calculated by $10^{0.09} / 10^{-0.03}$, since growth coefficient $A$ is $\log _{10}$ transformed). There is a weak 296 positive, but non-significant, relation between growth coefficient $A$ and zooplankton prey 297 production $\left(\log _{10}(A)=-0.06+1.39(Z P)\right.$, p-value $=0.07$, adjusted $\left.\mathrm{R}^{2}=0.07\right)$ and no 298 relationship between growth coefficient $A$ and zooplankton biomass (Fig. 6b and c). 


\section{Discussion}

300 Our results show weaker within- and between-species effects of temperature on growth of fish 301 than predicted from metabolic theory. The within-species effect of temperature varies between 302 species. The between-species effect of temperature is smaller when corrected for phylogenetic 303 signal and varies with fish guild and asymptotic length. Net primary production has a positive 304 effect on the average growth of fish. Below we first discuss the consequences of our findings for 305 models predicting fish response to climate warming. This section is followed by a more general 306 discussion.

\section{Consequences for models predicting fish response to climate warming}

308 The effects of changing temperatures with climate change on ectotherms are often predicted with 309 a high temperature sensitivity of all physiological rates, including growth. Yet, based on our 310 results, it is likely that there is a strong limit to the increase in growth with temperature as we find 311 weak within- and between-species effects of temperature in natural environments. Our results 312 hence suggest that the effect of temperature on growth is exaggerated in most climate change 313 projections.

314 We suggest that our results can be used as an upper boundary, i.e. reflecting the situation where 315 community re-assembly and temperature adaptations have run their course, for predictions of the 316 long-term effect of climate warming on fish growth. Most likely, average growth will initially 317 decrease with warming due to higher metabolic demands (Dillon, Wang \& Huey, 2010; Huey \& 318 Kingsolver, 2019). We can expect that the higher metabolic demands drive adjustments in fish life 319 history to counteract the effects of the new temperature regime. At the within-species level, these 320 adjustment may occur through acclimatization and adaptations (Seebacher, White \& Franklin, 321 2014). At the between-species level, adjustments may occur through community re-assembly 
322 generated by emigration, immigration and extirpation of species (Zhang, Takahashi, Hartvig \&

323 Andersen, 2017). Some of these processes, such as fish migrations to new environments, thermal

324 plasticity or a restructuring of ecological interactions, seem to occur fast (Frainer et al., 2017;

325 Pinsky, Worm, Fogarty, Sarmiento \& Levin, 2013; Seebacher et al., 2014), suggesting that average

326 fish growth in ecosystems is probably not much (positively or negatively) affected in the long-

327 term by temperature change with climate change. Yet, other climate change impacts, such as

328 changes in primary and secondary production (Stock et al., 2017), may affect growth rates and fish

329 life histories with climate change. Additionally, for invading fish to establish a viable population

330 in the new area they must be able to close their life cycle. Life cycle closure will depend on several

331 conditions, including the availability of suitable spawning locations that enable the larvae to

332 encounter sufficient food and adequate transport to suitable nursery areas.

333 Despite the weak effects of warming on growth, fish still need to cope with a higher metabolism.

334 Basal metabolism is predicted to increase with temperature with a $Q_{10} \approx 2.5$ (Brown et al., 2004),

335 whereas resting metabolism across teleost fish species has been found to increase with a $Q_{10} \approx 1.8$

336 (Clarke \& Johnston, 1999). Individual fish hence need to consume more food per unit time in

337 warmer waters. Increased consumption in warmer waters may be achieved by increased enzymatic

338 activities and hence digestive capacity, or enhanced activity levels (e.g. higher velocity (Dell,

339 Pawar \& Savage, 2014) or lower water viscosity) and hence higher clearance rates. Higher activity

340 and metabolic levels will decrease trophic efficiency (Barneche \& Allen, 2018). Therefore, despite

341 limited change in average growth for some fish guilds, their ecological performance changes

342 towards faster but less efficient transfer of energy in warmer systems. This will likely decline the

343 biomass of populations and communities and potential fisheries production, sensu Lotze et al.

344 (2019). 
346 We hypothesized that the typical within-species effect of temperature on growth is stronger, and

347 hence closer to the metabolic predictions, than the between-species effect, which is lower due to 348 evolutionary adaptation. We find no support for our hypothesis as the within-species effect is 349 generally weaker than the between-species effect, despite substantial variation between species in 350 the within-species effect of temperature on growth. From our analysis, we are unable to determine 351 if the within-species response is weak simply as a result of constraints in food availability (or other 352 ecological factors) or due to counter gradient variation in growth. The latter would imply genetic 353 variation within species that counteracts the effects of temperature (Conover \& Present, 1990).

354 The between-species effect of temperature on growth is also weaker than the metabolic predictions 355 and varies between fish guilds. Growth in elasmobranchs and, to a lesser extent, small pelagics 356 largely follows the metabolic predictions, whereas growth in large demersal fish is weakly 357 dependent on temperature ( $Q_{10}$ of 1.1 , with data spanning a $30^{\circ} \mathrm{C}$ temperature range). If the weak 358 temperature effect on large demersal fish is just a constraint in food availability (or any other 359 ecological factor), it would imply that large demersal fish species in warm water have a metabolic 360 capacity to grow that is approximately 15 times higher $\left(Q_{10}=2.5\right.$ over a $30^{\circ} \mathrm{C}$ temperature 361 gradient) than their observed growth. This overcapacity is unlikely without costs (Clarke, 2003) 362 and we expect natural selection to have operated; warmer habitats select for life histories with a 363 lower temperature-corrected growth capacity.

364 The between-species effect of temperature is lower when corrected for phylogenetic signal, 365 suggesting that at low and/or high temperatures a phylogenetic group is dominant and driving the 366 slope of the overall relationship. We expect that this is because fast-growing large pelagic fish, 367 which are phylogenetically related (Rabosky et al., 2018), mainly occur in warm waters. 
368 Potentially, slow-growing deep-living fish may be important for the phylogenetic predictions in

369 cold waters, but their phylogenetical relatedness is less strong.

370 The weak within- and between-species effects of temperature on growth do not invalidate

371 temperature effects as predicted by metabolic theory at the individual level. It may be expected

372 that any fish under laboratory conditions, or with climate warming, may initially increase its

373 growth rate with temperature in a manner consistent with metabolic theory. Such increases of fish

374 growth have been observed in temperature-size rule experiments (Atkinson, 1994). Our work

375 rather suggests that the growth trajectories with temperature as predicted by metabolic theory are

376 not sustainable in an ecosystem context, potentially the result of evolutionary adaptation of species

377 to their habitats and selection of life histories through community assembly. The weak between-

378 species effects of temperature on growth, relative to the metabolic predictions, confirm some

379 earlier studies (Sibly et al. (2015) with a $Q_{10}$ of 1.5 and Edgar \& Shaw (1995) with a $Q_{10}$ of 1.7

380 through the range $15-25^{\circ} \mathrm{C}$ ), whereas Clarke (2017) found a stronger temperature-sensitivity of

381 growth $\left(Q_{10}\right.$ of 2$)$. Our results provide a potential explanation for these variable results as we

382 observe that growth-temperature relationships vary with asymptotic size, fish guild and phylogeny

383 and hence depend on the fish species and predictor variables examined.

384 The effect of food availability on growth

385 We find a positive effect of net primary production on average fish growth (a 4-fold increase in 386 NPP leads to a 1.3-fold increase in growth) and no relationship between growth and zooplankton 387 production or biomass. The weak positive correlation between net primary production and fish 388 growth is supported by a recent global analysis of reef fish growth, where growth variation of reef 389 fish species weakly increased with regional variation in net primary production (Morais \& 390 Bellwood, 2018). The absence of a relation between zooplankton biomass and growth is surprising. 
391 The absence of such a relationship may be related to uncertainty in the prey biomass estimates and 392 to uncertainty regarding the extent to which our modeled data reflect the actual food availability. 393 Alternatively, growth rates may be partly decoupled from prey availability as fish do not optimize 394 growth but fitness (Giacomini, Shuter \& Lester, 2013). Because feeding often is associated with a 395 higher predation risk, fish may tend to prioritize a reduction in predation mortality over increased 396 growth rate when resources are abundant (Biro, Post \& Abrahams, 2005).

397 Data uncertainty

398 Previous work that evaluated the precision and accuracy of FishBase has suggested that published 399 data of life history parameters in FishBase through database entries often are unbiased even though 400 they are imprecise (Thorson, Cope \& Patrick, 2014). Ideally, we should have included parameter 401 imprecision in our analysis by adding error estimates of the von Bertalanffy parameters to our 402 models. Yet, these error estimates are not recorded in FishBase, and, they are often not reported in 403 the more historical "source" publications either. Without these error estimates, our analyses have 404 likely reduced power and increased unexplained variance, but we expect that the slopes of the 405 temperature-growth relationships are unbiased. The use of average ambient temperatures is 406 another source of uncertainty as temperature varies within a region and fish may migrate between 407 regions. Fish are further not uniformly distributed within an ecoregion, but rather occupy a 408 particular habitat subset that may differ in its temperature characteristics (Guzzo, Blanchfield, \& 409 Rennie, 2017). Nevertheless, our results are robust against some temperature variation, which is 410 exemplified by little difference in $Q_{10}$ when using the coldest or warmest calendar quarter per 411 ecoregion instead of a yearly average (appendix S1, Table S1.5). Many of the fish species in our 412 analysis are exploited and fishing is another source of uncertainty as it can influence growth rates 413 by removing conspecifics, thus decreasing density-dependent growth. The impact of fishing could 
414 result in biased growth-temperature estimates, if, in our database, fish in warmer systems are 415 consistently less exploited than fish in colder waters. We are not aware of studies that suggest such 416 a pattern.

417 Our statistical analyses did not consider potential non-linearities in the shape of the growth curve 418 with temperature. Temperatures experienced in the field may exceed the performance peak of a 419 species, which can make the linear growth-temperature curve flat. There were no indications that 420 such non-linear within-species relationships between growth and temperature were generic. A 421 separate species-specific analysis shows support for a decline at the warmer edge in 6 out of 46

422 fish species with highest quality data (appendix S4, Fig S4.1). There was no support for a non423 linear between-species relationship between temperature and growth (appendix S4).

\section{Conclusion}

425 Our results show weak within- and between-species effects of temperature on growth that do not 426 match metabolic predictions. These findings indicate that metabolic models of the effects of 427 temperature on growth will overestimate the effect of temperature when the models are used to 428 examine the effect of temperature on growth in space (across ecosystems) or in time (temperature 429 change with climate change). Our results suggest that a proper understanding of how fish growth 430 changes globally in response to climate change not only requires a correct description of the 431 physiological response to temperature (Lefevre, McKenzie \& Nilsson, 2017), but also of the

432 ecological dynamics and phylogenetic constraints. It is crucial to understand the processes of 433 environmental and ecological filtering that select the set of viable combinations of life-history 434 characters in a given environment and temperature. 
435 Acknowledgements: We thank CA Stock and C Petrik for the GFDL-ESM2.6 and COBALT

436 model output, MK Thomas for advice on the statistical analyses, A Phillimore for comments on

437 an earlier version of the manuscript and FishBase for all efforts to collate data on fish parameters.

438 PDvD and KHA were funded by the Centre for Ocean Life, a VKR center of excellence supported

439 by the Villum Foundation. PDvD received additional funding from the People Programme (Marie

440 Curie Actions) under Research Executive Agency grant agreement number

441609405 (COFUNDPostdocDTU).

442 Data availability Statement: All data used for the analyses, including the von Bertalanffy fish

443 growth parameters (as downloaded on 27 April 2018 from 'rfishbase'), and code for all data

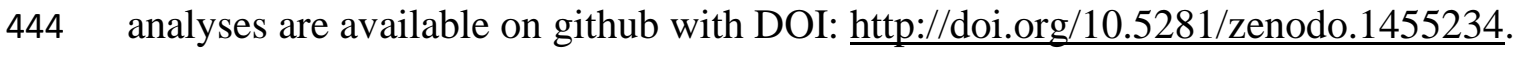

445 Biosketch: Daniël van Denderen is a postdoctoral researcher at the Centre for Ocean Life in

446 Denmark. His research focuses on the importance of pelagic and benthic habitats for marine fish

447 communities, food webs and fisheries production. The Centre for Ocean Life, where most of the

448 authors are affiliated, aims to develop mechanistic trait-based approaches to study life in the ocean. 


\section{References}

Andersen, K. H. (2019). Fish ecology, evolution, and exploitation. Princeton University Press.

Arendt, J. D. (1997). Adaptive intrinsic growth rates: an integration across taxa. The Quarterly Review of Biology, 72(2), 149-177.

Atkinson, D. (1994). Temperature and organism size: a biological law for ectotherms? Advances in Ecological Research, 25, 1-58.

Barneche, D. R., \& Allen, A. P. (2018). The energetics of fish growth and how it constrains food-web trophic structure. Ecology Letters, 21(6), 836-844.

Bates, D., Mächler, M., Bolker, B., \& Walker, S. (2015). Fitting linear mixed-effects models using lme4. Journal of Statistical Software, 67(1), 1-48.

Behrenfeld, M. J., \& Falkowski, P. G. (1997). Photosynthetic rates derived from satellite-based chlorophyll concentration. Limnology and Oceanography, 42(1), 1-20.

Biro, P. A., Post, J. R., \& Abrahams, M. V. (2005). Ontogeny of energy allocation reveals selective pressure promoting risk-taking behaviour in young fish cohorts. Proceedings of the Royal Society B: Biological Sciences, 272(1571), 1443-1448.

Blanchard, J. L., Jennings, S., Holmes, R., Harle, J., Merino, G., Allen, J. I., ... Barange, M. (2012). Potential consequences of climate change for primary production and fish production in large marine ecosystems. Phil. Trans. R. Soc. B, 367(1605), 2979-2989.

Boettiger, C., Lang, D. T., \& Wainwright, P. C. (2012). rfishbase: exploring, manipulating and visualizing FishBase data from R. Journal of Fish Biology, 81(6), 2030-2039.

Brown, J. H., Gillooly, J. F., Allen, A. P., Savage, V. M., \& West, G. B. (2004). Toward a metabolic theory of ecology. Ecology, 85(7), 1771-1789.

Carozza, D. A., Bianchi, D., \& Galbraith, E. D. (2019). Metabolic impacts of climate change on 
marine ecosystems: Implications for fish communities and fisheries. Global Ecology and Biogeography, 28(2), 158-169.

474 Chang, J., Rabosky, D. L., Smith, S. A., \& Alfaro, M. E. (2019). An R package and online 475 resource for macroevolutionary studies using the ray-finned fish tree of life. Methods in Ecology and Evolution, 10(7), 1118-1124.

Charnov, E. L., Gislason, H., \& Pope, J. G. (2013). Evolutionary assembly rules for fish life histories. Fish and Fisheries, 14(2), 213-224.

Cheung, W. W. L., Sarmiento, J. L., Dunne, J., Frölicher, T. L., Lam, V. W. Y., Deng Palomares, M. L., ... Pauly, D. (2013). Shrinking of fishes exacerbates impacts of global ocean changes on marine ecosystems. Nature Climate Change, 3, 254-258.

Cheung, W. W. L., Bruggeman, J., \& Butenschön, M. (2018). Projected changes in global and national potential marine fisheries catch under climate change scenarios in the twenty-first century. In Barange. M., Bahri, T., Beveridge, M.C., Cochrane, K.L., Funge-Smith, S., \& Poulain, F. (Eds.) Impacts of climate change on fisheries and aquaculture: synthesis of current knowledge, adaptation and mitigation options. FAO Fisheries and Aquaculture Technical Paper No. 627. FAO, Rome. 628 pp.

Clarke, A. (2003). Costs and consequences of evolutionary temperature adaptation. Trends in Ecology \& Evolution, 18(11), 573-581.

Clarke, A. (2017). Principles of thermal ecology - Temperature, energy and life. Oxford University Press.

Clarke, A., \& Johnston, N. M. (1999). Scaling of metabolic rate with body mass and temperature in teleost fish. Journal of Animal Ecology, 68(5), 893-905.

Compagno, L. J. V. (2008). Pelagic elasmobranch diversity. Ch. 3. In. Camhi. M.D., Pikitch. 

Conservation. Blackwell Publishing Ltd.

Conover, D. O., \& Present, T. M. C. (1990). Countergradient variation in growth rate: compensation for length of the growing season among Atlantic silversides from different latitudes. Oecologia, 83(3), 316-324.

Dell, A. I., Pawar, S., \& Savage, V. M. (2014). Temperature dependence of trophic interactions are driven by asymmetry of species responses and foraging strategy. Journal of Animal Ecology, 83(1), 70-84.

Dillon, M. E., Wang, G., \& Huey, R. B. (2010). Global metabolic impacts of recent climate warming. Nature, 467(7316), 704-706.

Edgar, G. J., \& Shaw, C. (1995). The production and trophic ecology of shallow-water fish assemblages in southern Australia I. Species richness, size-structure and production of fishes in Western Port, Victoria. Journal of Experimental Marine Biology and Ecology, 194(1), 53-81.

Felsenstein, J. (1985). Phylogenies and the comparative method. The American Naturalist, $125(1), 1-15$.

Frainer, A., Primicerio, R., Kortsch, S., Aune, M., Dolgov, A. V, Fossheim, M., \& Aschan, M. M. (2017). Climate-driven changes in functional biogeography of Arctic marine fish communities. Proceedings of the National Academy of Sciences, 114(46), 12202-12207.

Froese, R. (2006). Cube law, condition factor and weight-length relationships: history, metaanalysis and recommendations. Journal of Applied Ichthyology, 22(4), 241-253.

Froese, R., \& Pauly, D. (2018). FishBase World Wide Web electronic publication. www.fishbase.org, version (10/2018). www.Fishbase.org. 
Giacomini, H. C., Shuter, B. J., \& Lester, N. P. (2013). Predator bioenergetics and the prey size spectrum: do foraging costs determine fish production? Journal of Theoretical Biology, 332, 249-260.

Grady, J. M., Enquist, B. J., Dettweiler-Robinson, E., Wright, N. A., \& Smith, F. A. (2014). Evidence for mesothermy in dinosaurs. Science, 344(6189), 1268-1272.

Guzzo, M. M., Blanchfield, P. J., \& Rennie, M. D. (2017). Behavioral responses to annual temperature variation alter the dominant energy pathway, growth, and condition of a coldwater predator. Proceedings of the National Academy of Sciences, 114(37), 9912-9917.

Hadfield, J. D. (2010). MCMC methods for multi-response generalized linear mixed models: the MCMCglmm R package. Journal of Statistical Software, 33(2), 1-22.

Huey, R. B., \& Kingsolver, J. G. (2019). Climate warming, resource availability, and the metabolic meltdown of ectotherms. The American Naturalist, 194(6), E140-E150.

Jobling, M. (1997). Temperature and growth: modulation of growth rate via temperature change. Seminar Series-Society for Experimental Biology, 61, 225-254.

Kingsolver, J. G. (2009). The well-temperatured biologist. The American Naturalist, 174(6), $755-768$.

Kremer, C. T., Thomas, M. K., \& Litchman, E. (2017). Temperature- and size-scaling of phytoplankton population growth rates: reconciling the Eppley curve and the metabolic theory of ecology. Limnology and Oceanography, 62(4), 1658-1670.

Kuznetsova, A., Brockhoff, P. B., \& Christensen, R. H. B. (2017). lmerTest package: tests in linear mixed effects models. Journal of Statistical Software, 82(13), 1-26.

Lefevre, S., McKenzie, D. J., \& Nilsson, G. E. (2017). Models projecting the fate of fish populations under climate change need to be based on valid physiological mechanisms. 
Global Change Biology, 23(9), 3449-3459.

542

543

544

545

546

547

548

549

550

551

552

553

554

555

556

557

558

559

560

561

562

563

Lotze, H. K., Tittensor, D. P., Bryndum-Buchholz, A., Eddy, T. D., Cheung, W. W. L., Galbraith, E. D., ... Blanchard, J. L. (2019). Global ensemble projections reveal trophic amplification of ocean biomass declines with climate change. Proceedings of the National Academy of Sciences, 116(26), 12907-12912.

Morais, R. A., \& Bellwood, D. R. (2018). Global drivers of reef fish growth. Fish and Fisheries, 19(5), 874-889.

O’Gorman, E. J., Petchey, O. L., Faulkner, K. J., Gallo, B., Gordon, T. A. C., Neto-Cerejeira, J., ... Woodward, G. (2019). A simple model predicts how warming simplifies wild food webs. Nature Climate Change, 9(8), 611-616.

Pinsky, M. L., Worm, B., Fogarty, M. J., Sarmiento, J. L., \& Levin, S. A. (2013). Marine taxa track local climate velocities. Science, 341(6151), 1239-1242.

Rabosky, D. L., Chang, J., Title, P. O., Cowman, P. F., Sallan, L., Friedman, M., ... Alfaro, M. E. (2018). An inverse latitudinal gradient in speciation rate for marine fishes. Nature, 559(7714), 392-395.

Seebacher, F., White, C. R., \& Franklin, C. E. (2014). Physiological plasticity increases resilience of ectothermic animals to climate change. Nature Climate Change, 5, 61.

Sibly, R. M., Baker, J., Grady, J. M., Luna, S. M., Kodric-Brown, A., Venditti, C., \& Brown, J. H. (2015). Fundamental insights into ontogenetic growth from theory and fish. Proceedings of the National Academy of Sciences , 112(45), 13934-13939.

Spalding, M. D., Fox, H. E., Allen, G. R., Davidson, N., Ferdaña, Z. A., Finlayson, ... Robertson, J. (2007). Marine ecoregions of the world: a bioregionalization of coastal and shelf areas. BioScience, 57(7), 573-583. 
564 Stock, C. A., Dunne, J. P., \& John, J. G. (2014). Global-scale carbon and energy flows through 565 the marine planktonic food web: an analysis with a coupled physical-biological model. 566 Progress in Oceanography, 120, 1-28.

567 Stock, C. A., John, J. G., Rykaczewski, R. R., Asch, R. G., Cheung, W. W. L., Dunne, J. P., ... 568 Watson, R. A. (2017). Reconciling fisheries catch and ocean productivity. Proceedings of 569 the National Academy of Sciences, 114(8), E1441-E1449.

570 Thorson, J. T., Cope, J. M., \& Patrick, W. S. (2014). Assessing the quality of life history 571 information in publicly available databases. Ecological Applications, 24(1), 217-226.

572 van de Pol, M., \& Wright, J. (2009). A simple method for distinguishing within-versus between$573 \quad$ subject effects using mixed models. Animal Behaviour, 77(3), 753.

574 Von Bertalanffy, L. (1957). Quantitative laws in metabolism and growth. The Quarterly Review $575 \quad$ of Biology, 32(3), 217-231.

576 West, G. B., Brown, J. H., \& Enquist, B. J. (2001). A general model for ontogenetic growth. $577 \quad$ Nature, $413(6856), 628$.

578 Zhang, L., Takahashi, D., Hartvig, M., \& Andersen, K. H. (2017). Food-web dynamics under 579 climate change. Proceedings of the Royal Society B: Biological Sciences, 284(1867), $580 \quad 20171772$.

581 Zuur, A., Ieno, E. N., Walker, N., Saveliev, A. A., \& Smith, G. M. (2009). Mixed effects models $582 \quad$ and extensions in ecology with R. Springer Science \& Business Media. 
$583 \quad$ Figures

584 

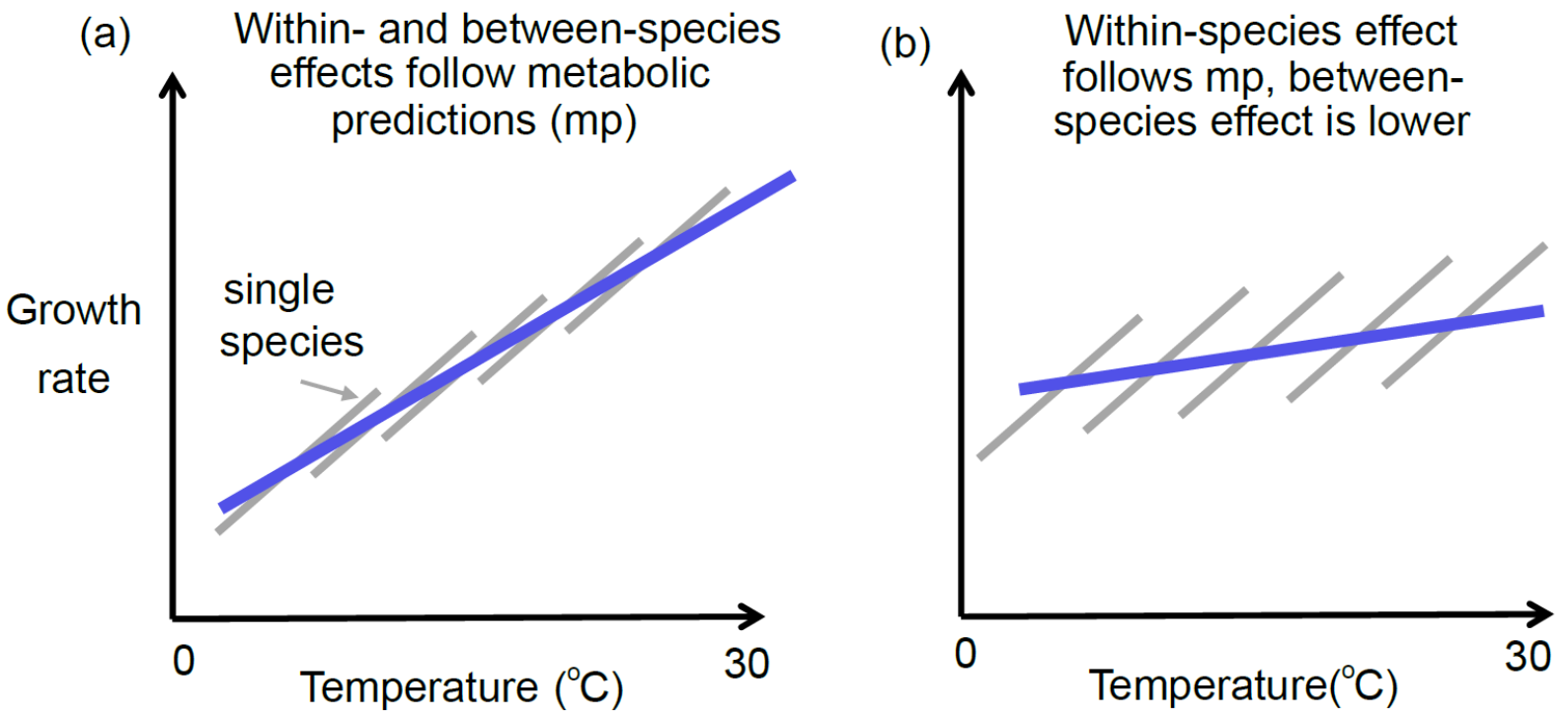

586 Figure 1. Potential growth response of different species with temperature where the within- and 587 between-species effects follow the metabolic predictions (a) or where the between-species 588 response (blue line) is lower (b). The grey lines show the increasing part of the thermal 589 performance curve. 


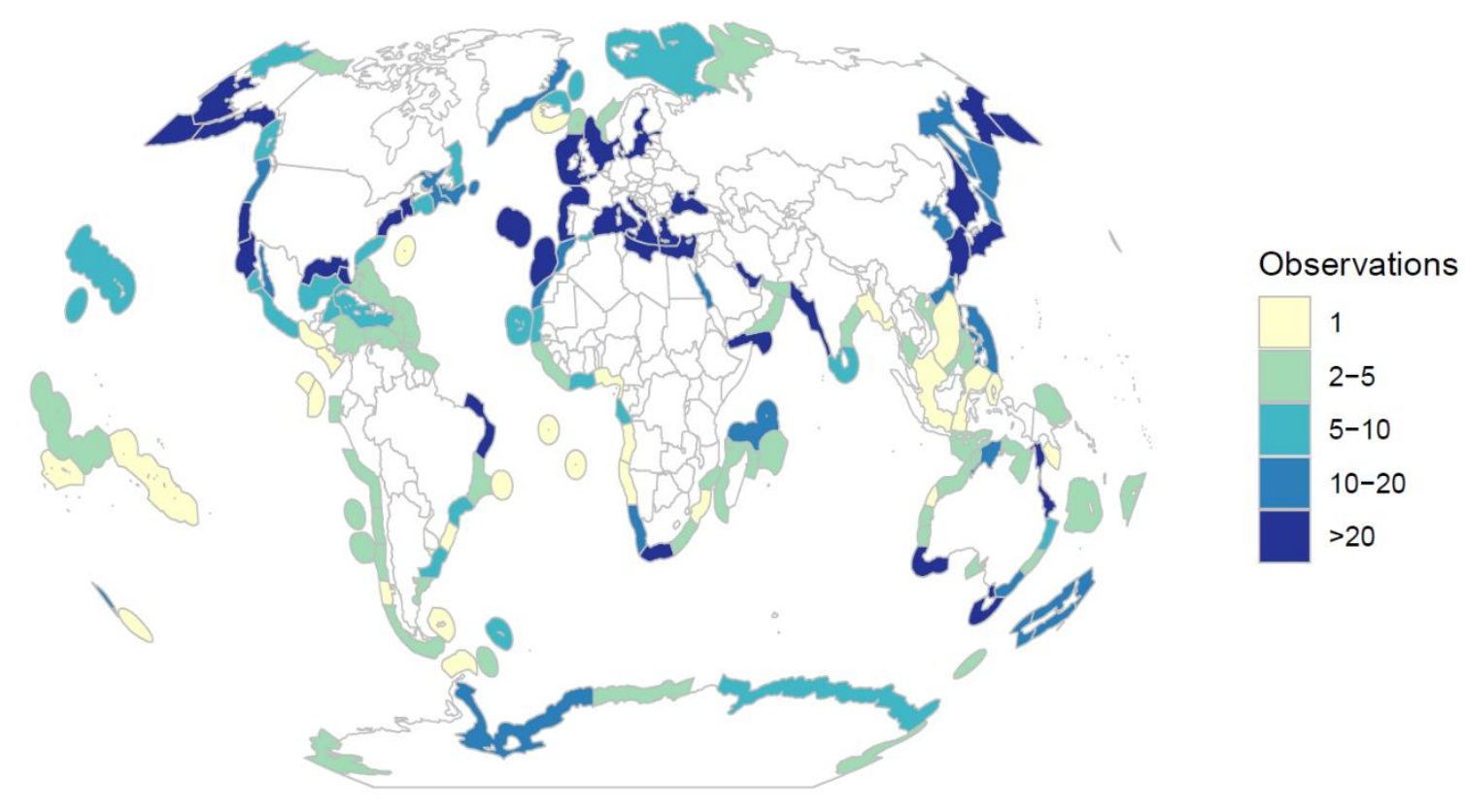

591

592 Figure 2. Number of von Bertalanffy parameter observations specified per marine ecoregion (total

593 observations is 2517 for 771 species). The observations were linked to a marine ecoregion, or to

594 two neighboring ecoregions based on sampling locality (if two ecoregions, we only coupled the 595 observation to one of these regions to produce the figure). 
(a)

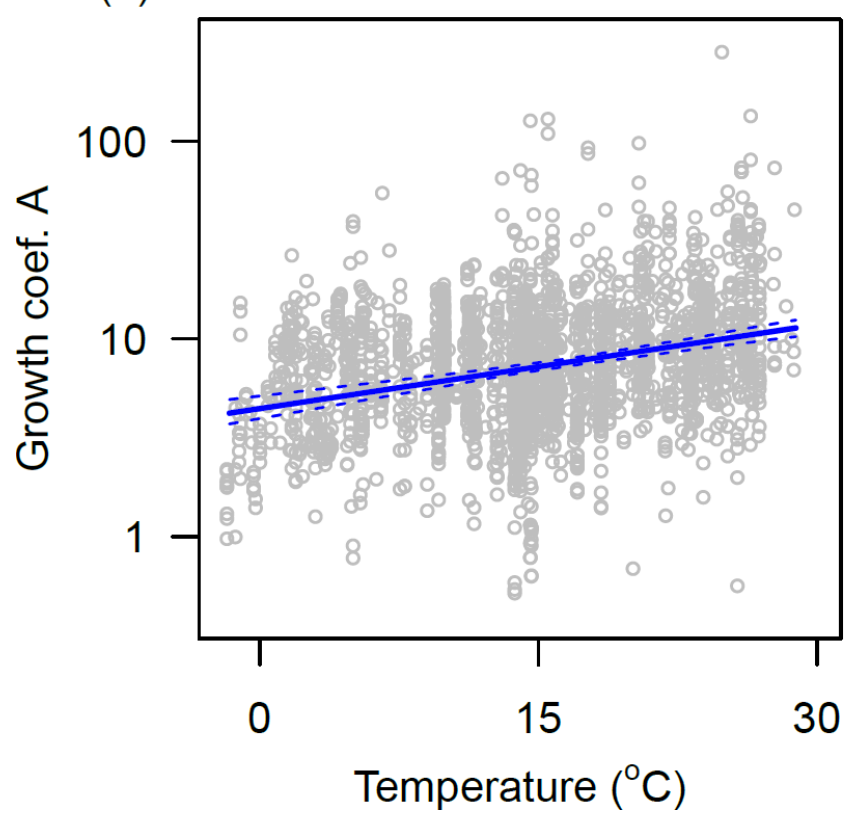

(b)

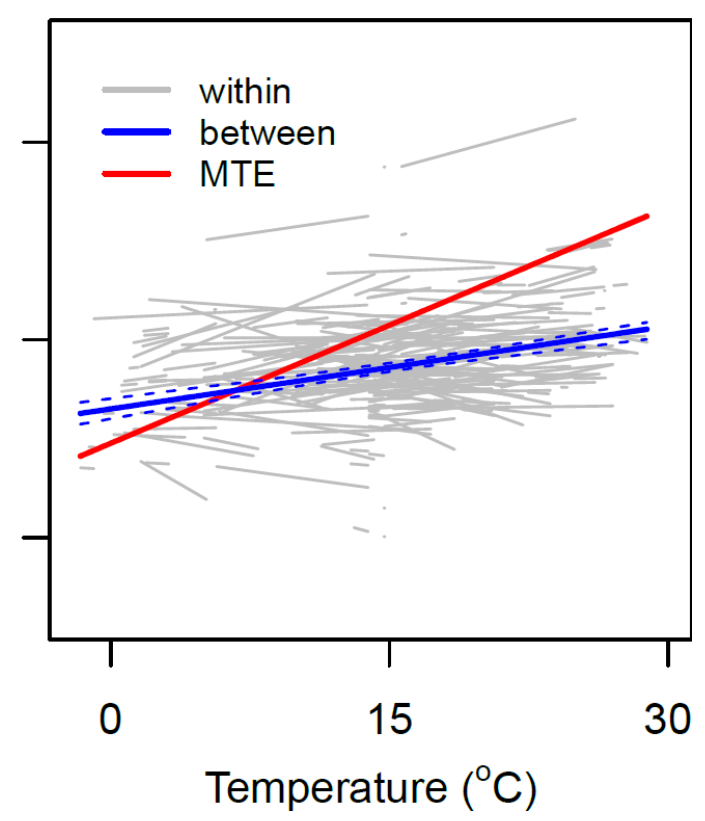

598 Figure 3. Relationships between growth coefficient $A$ and temperature. The between species effect 599 is shown with a blue solid line in (a, b); blue dashed lines show the bootstrapped 95\% confidence 600 interval using the function 'bootMer' in R-package 'Ime4'. The positive between species effect of 601 temperature on growth corresponds to a $Q_{10}=1.38,95 \%$ CI 1.29-1.49 (M1). The within-species 602 effect of temperature on growth coefficient $A$ is shown with grey solid lines in (b) based on M2 603 for the temperature range where data is available. The within-species effect corresponds to an 604 average $Q_{10}$ of 1.08 . The red line in (b) illustrates a $Q_{10}$ of 2.5 that corresponds to a temperature 605 scaling as predicted from metabolic theory with $A$ is 3 at $0{ }^{\circ} \mathrm{C}$. 


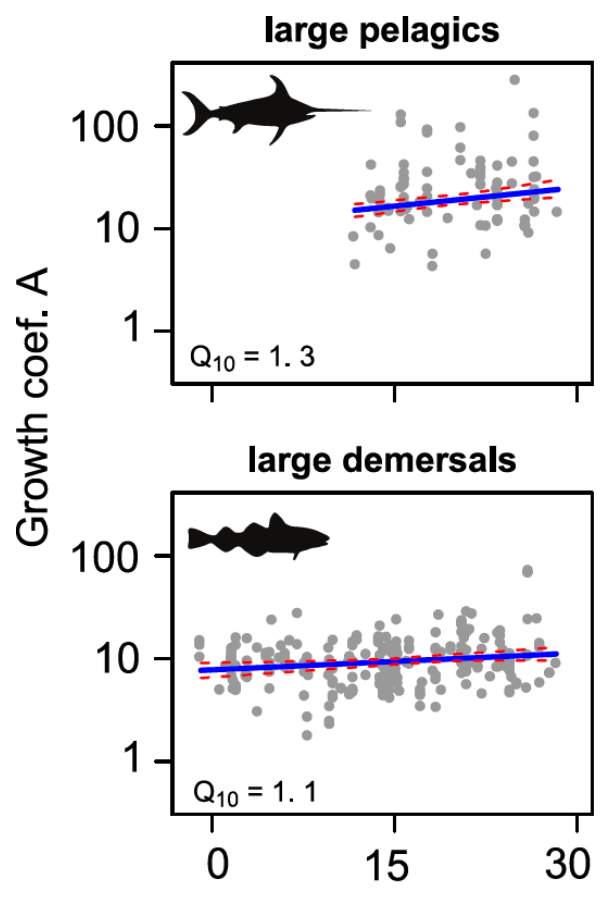

607

608

609

610

611 range for deep-living fish) are weakly affected by temperature. The blue lines show the

612 temperature effect on growth coefficient $A$ given an average $L_{\infty}$. The $95 \%$ confidence intervals

613 (red dashed lines) are estimated using the function 'bootMer' in R-package 'lme4'. The breakpoint

614 between small and large species is, for plotting purposes, set at $L_{\infty}=80 \mathrm{~cm}$. 
(a)

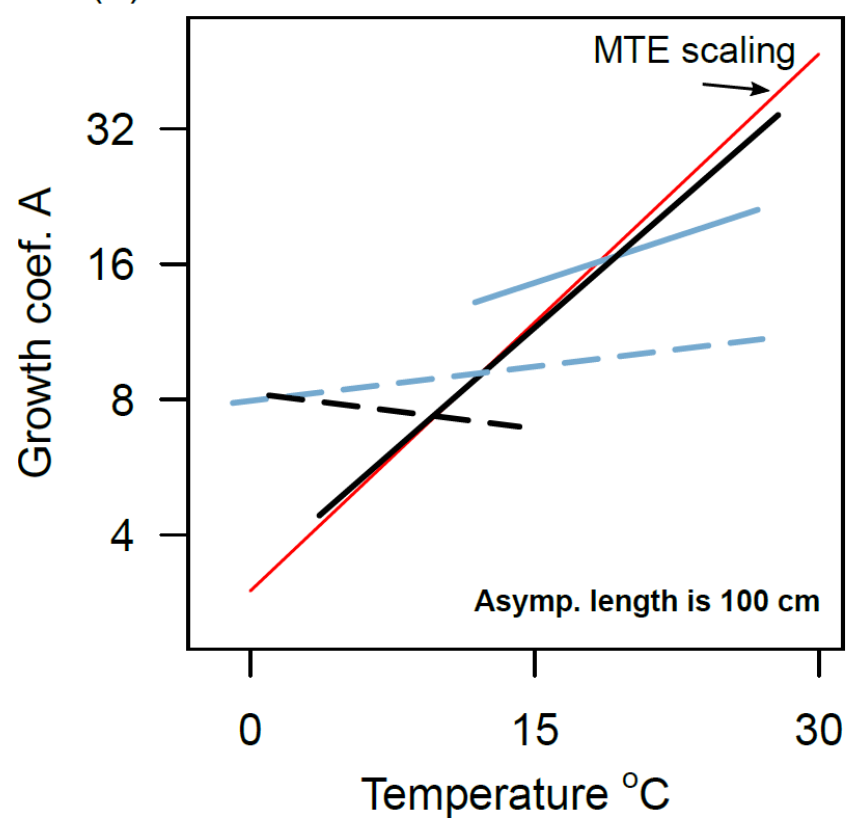

(b)

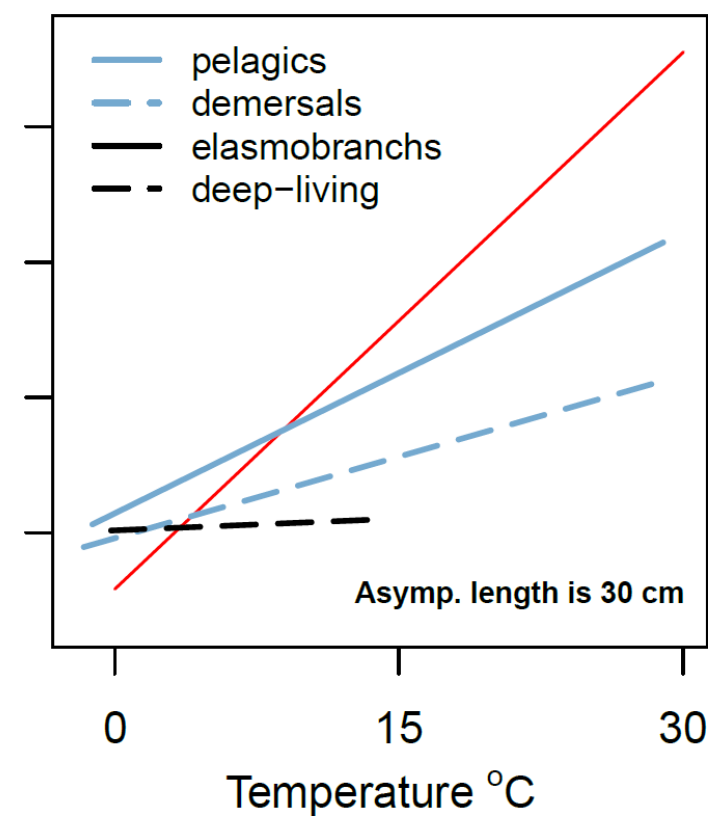

617 Figure 5. Predicted relationships between fish growth coefficient $A$ and temperature across guilds

618 for fish with $L_{\infty}=100 \mathrm{~cm}$ (a) or $30 \mathrm{~cm}$ (b) based on M4. The temperature effect is only shown in

619 the temperature range where data is available. The thin red lines illustrate a $Q_{10}$ of 2.5 that 620 corresponds to a temperature scaling as predicted from metabolic theory with $A$ is 3 at $0{ }^{\circ} \mathrm{C}$. 

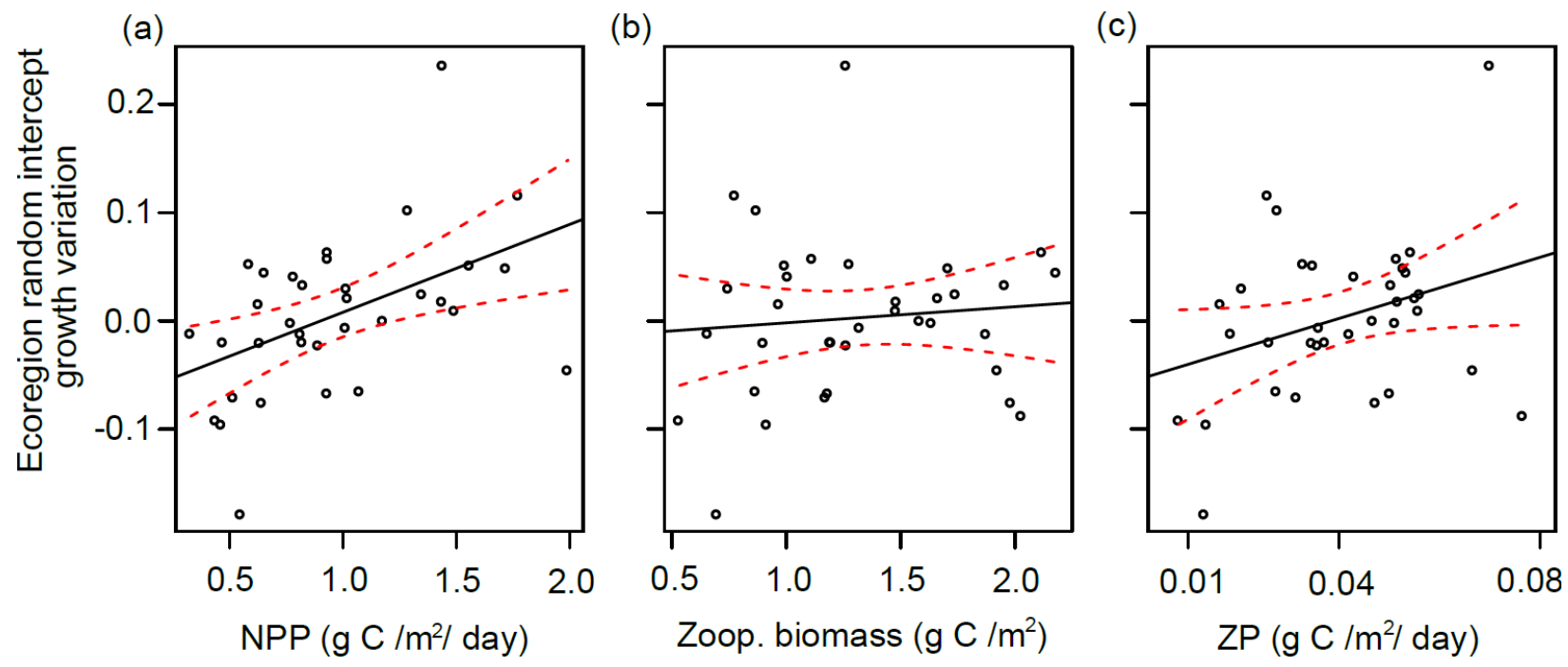

622 Figure 6. Relationships between the ecoregion random intercept growth values from M4 and net 623 primary production (NPP) (a), zooplankton biomass (b) and zooplankton production (ZP) (c). The 624 relationship between growth and NPP is statistically significant $\left(\log _{10}(A)=-0.07+\right.$ $6250.08(N P P), \mathrm{p}$-value $=0.005$, adjusted $\left.R^{2}=0.20\right)$ and remains positive and statistically significant 626 when the lowest and highest random intercept values are removed (not shown). The relationships 627 between growth and zooplankton biomass and production are not significant. Red dashed lines 628 show the $95 \%$ confidence interval. 


\section{Supplementary material information}

630 Appendix S1: supplementary figures and tables

631 Appendix S2: species-specific length-weight relationships

632 Appendix S3: environmental conditions

633 Appendix S4: non-linear relationships between growth and temperature

634 Appendix S5: visual inspections of model fit. 